\title{
Seismic Monitoring of the Atwood Building in Anchorage, Alaska
}

"Earthquakes don't kill people-buildings do."
Since the great Alaska earthquake
of 1964, scientists and engineers
have learned much about improving
structural design to accommodate
earthquake shaking, but we still
have much more to learn. The Ad-
vanced National Seismic System
(ANSS), under the leadership of the
U.S. Geological Survey, has been
launched to improve earthquake
monitoring of both ground and struc-
tural response to strong shaking in
an effort to save property and lives
in the future.

The devastating effects of earthquakes are well known in Alaska. The great March 27, 1964 (Good Friday), Alaska earthquake shook the ground for more than 4 minutes over a 50,000-square-mile zone of destruction and caused 131 deaths and as much as $\$ 500$ million (1964 dollars) in property damage. This magnitude 9.2 event, the largest earthquake ever recorded in the Northern Hemisphere, left scars on the landscape that are still visible today.

Much work has been done since 1964 to mitigate the damaging effects of earth-

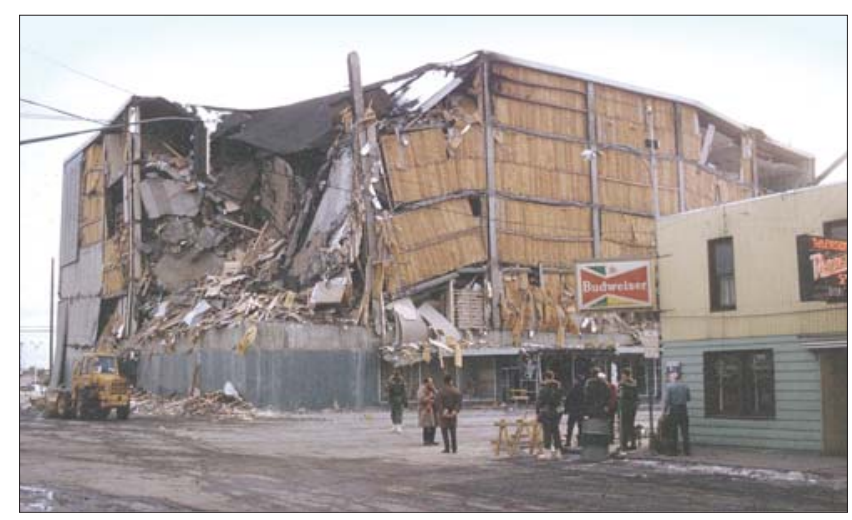

Wreckage of the J.C. Penney department store, Fifth Avenue and D Street, Anchorage. Building failed after sustained seismic shaking during the 1964 earthquake. At the time this photograph was taken, most of the rubble had been cleared from the street. USGS photograph by George Plafker. quakes, both in Alaska and nationwide. For example, earthquake monitoring networks have been established with real-time reporting capabilities, probabilistic seismic-hazard assessments have been performed, buildingcode seismic provisions have been updated and adopted, and emergency-response plans have been developed and practiced. The U.S. Geological Survey (USGS) and cooperating organizations have pursued extensive earthquake research in Alaska and elsewhere, but despite all these advances, further progress is needed, particularly in the area of earthquake engineering of structures.

Earthquake-resistant design is the first line of defense in reducing community losses from earthquakes. To improve building safety, better knowledge is needed of both the mechanics of ground shaking and the response of structures to that shaking. Seismologists are seeking to mathematically model how seismic waves propagate through the Earth, so that the strength and duration of future ground shaking at a site can be more accurately predicted. Additionally, engineers are working to understand how their designed structures respond to strong ground shaking, so that both existing and new buildings can be strengthened adequately to withstand projected earthquake shaking.

Study and analysis of how a structure responds to strong ground shaking is limited today by the scarcity of earthquake recordings from within buildings. Currently, only a few buildings in the United States have been extensively instrumented to record their performance during earthquakes. This scarcity of directly obtained data means that engineers must infer the characteristics

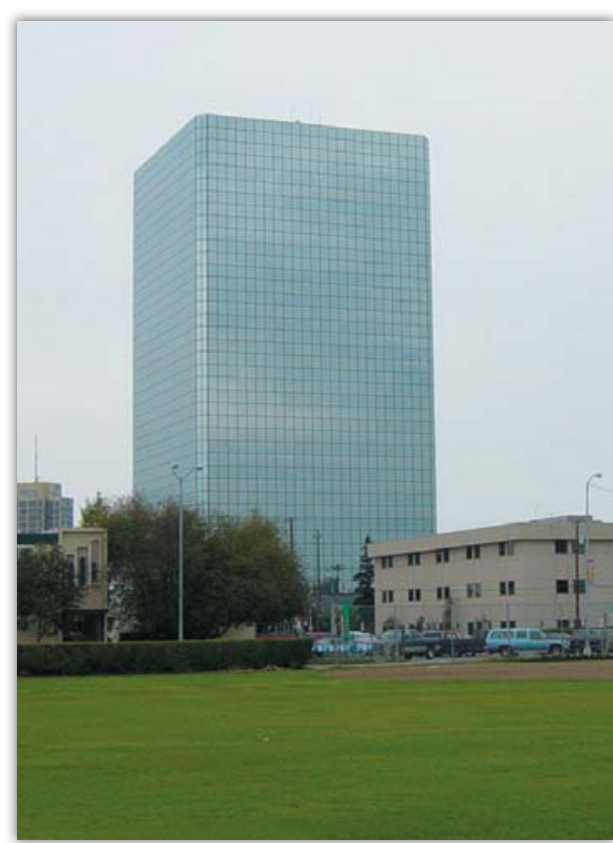

The 20-story Robert Atwood Government Building in downtown Anchorage, built in 1982, is the most fully instrumented building yet monitored by the Advanced National Seismic System.

of structural response to earthquakes when they design buildings.

Recently, the Federal Government has provided funding for a pilot program to improve ground and structural recording of earthquake-induced shaking in high-risk urban areas. This effort, known as the Advanced National Seismic System (ANSS), has an eventual goal of placing 3,000 strongmotion recorders in buildings and other engineered structures around the United States, as well as 3,000 instruments at "free field" sites (that is, recordings on the ground free from the influence of engineered structures). Together, these structural monitoring systems will provide engineers with critical answers as to how particular building types respond to strong ground shaking.

\section{ANSS and the Atwood Building}

One of the first buildings to be fully instrumented under the ANSS is the Robert Atwood Government Building in Anchor- 


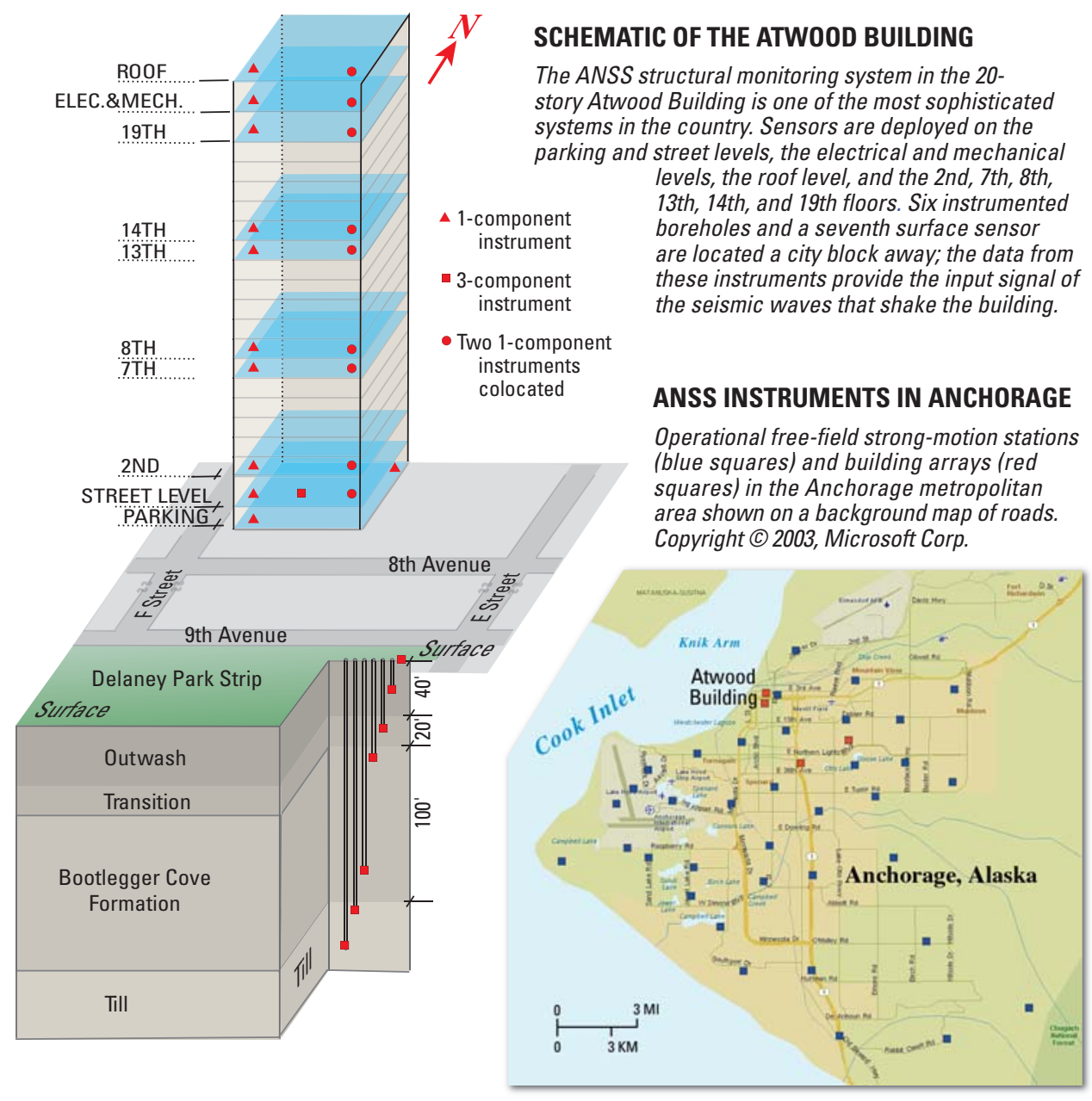

age, Alaska, a 20-story steel-frame structure with a single-story basement and a reinforced-concrete foundation. The ANSS structural monitoring system in the Atwood Building is one of the most sophisticated monitoring systems in the country. Sensors are deployed on 10 levels of the building, equipped at each level to detect motion in the east-west and north-south directions; vertical direction of motion is monitored in the basement.

Specifically, the instrumentation within the building is designed to record (1) lateral swaying, (2) twisting, (3) rocking, and (4) drift (displacement) between selected pairs of adjacent floors and average drift between any number of floors. The swaying, twisting, and drift are related directly to the shaking of the building from seismic waves, and the rocking is related to interaction of the building with the underlying soil. Measuring the rocking is particularly important for incorporating the effect of soil-structure interaction in the design of structures.

The building sensors are complemented by an array of buried, three-component sensors in six boreholes ranging in depth from 15 to 200 feet (5-60 meters), with a are located approximately a city block from the building, sufficiently removed that the sensor records are unaffected by shaking of the building itself. The borehole data thus record the input signal of the seismic waves impinging on the building. In combination, the borehole and building-response data will allow engineers to study the interaction between the soil and the structure. Data recorded by both the borehole and building arrays are transmitted to a USGS central processing facility in Menlo Park, California, where they are analyzed and made available to the engineering community.

The Atwood Building was selected for ANSS monitoring because it represents a common class of engineered structures and is located in a highly active seismic region. Anchorage is continually affected by earthquakes occurring both nearby and tens to hundreds of miles (kilometers) away. The subduction zone that dips beneath Anchorage is a source of numerous earthquakes, and the crustal faults that overlie this zone are a less frequent, but equally potent, source of strong seismic shaking. Moreover, the Denali Fault in central Alaska and

related thrust faults have been unusually active during the past 2 years, spawning the magnitude 7.9 earthquake of November 3, 2003, and numerous aftershocks. Much like the tactic of a fisherman putting his hook into the water where he thinks the fish are biting, the Anchorage area provides one of the best localities in the United States to catch the measurements of strong earthquake shaking that engineers so urgently need.

\section{Lessons for the Lower Forty-Eight States}

The lessons learned from the Atwood Building will be applicable to buildingdesign issues throughout the United States. Capturing the behavior of this structure at this site will allow engineers to assess the performance of the building during an earthquake, determine how best to retrofit or strengthen existing similar structures, and learn how to create new designs that are more earthquake resistant.

If fully implemented, the ANSS will instrument hundreds of buildings in this fashion. Through the ANSS, the USGS and its cooperators are poised to greatly expand strong-motion recordings in highrisk urban areas, both on the ground and in buildings, and thereby provide the engineering community with the data they need to improve building codes and structuraldesign practices.

Mehmet Çelebi, Jill McCarthy, Niren Biswas, Lisa Wald, Robert Page, and Jamison Steidl

Edited by George A. Havach

Graphic design by Susan Mayfield, Sara Boore, and Lisa Wald

\section{COOPERATING ORGANIZATIONS}

Alaska Earthquake Information Center, Geophysical Institute,

University of Alaska, Fairbanks

Institute for Crustal Studies, University of California, Santa Barbara

University of Alaska, Anchorage

\section{For more information, contact: \\ Earthquake Hazards Team U.S. Geological Survey Menlo Park, CA 94025 \\ http://earthquake.usgs.gov/}

Earthquake Information Hotline: (650) 329-4085

Advanced National Seismic System http://www.anss.org/

This Fact Sheet and any updates to it are available online at:

http://pubs.usgs.gov/fs/2004/3103/ 